\title{
Exclusive breast-feeding and sociodemographic characteristics are associated with dietary patterns in children aged 4-7 years
}

\author{
Sarah Aparecida Vieira ${ }^{1, *}$, Poliana Cristina de Almeida Fonseca ${ }^{1}$, Cristiana \\ Santos Andreoli ${ }^{2}$, Helen Hermana Miranda Hermsdorff' ${ }^{1}$, Andréia Queiroz Ribeiro ${ }^{1}$, \\ Patrícia Feliciano Pereira ${ }^{1}$, Silvia Eloiza Priore ${ }^{1}$ and Sylvia do Carmo Castro Franceschini ${ }^{1}$ \\ ${ }^{1}$ Department of Nutrition, Federal University of Viçosa, Avenue Ph Rolfs, University Campus, Viçosa - MG, \\ 36570-900, Brazil: ${ }^{2}$ Department of Technology in Gastronomy, Federal Institute of Minas Gerais, Ouro \\ Preto, MG, Brazil
}

Submitted 8 May 2017: Final revision received 5 October 2018: Accepted 22 0ctober 2018: First published online 30 January 2019

\begin{abstract}
Objective: To identify the dietary patterns of children aged 4-7 years and verify their association with sociodemographic characteristics, lifestyle habits and exclusive breast-feeding (EBF).

Design: A cross-sectional study nested within a cohort, performed with Brazilian children aged 4-7 years. The children were re-evaluated at age 4 to 7 years and food patterns were identified a posteriori through principal component analysis. The predictive variables were related to socio-economic characteristics, lifestyle habits and duration of EBF.

Setting: Viçosa, Minas Gerais, Brazil.

Participants: Representative sample of 403 children followed up by the Lactation Support Program from the Extension Program of the Universidade Federal de Viçosa during the first 6 months of life.

Results: Five dietary patterns were identified: 'Traditional', 'Unhealthy', 'Milk and chocolate', 'Snack' and 'Healthy'. Children who did not receive EBF until they were at least 4 months old had a higher adherence to the 'Unhealthy' and 'Snack' patterns, and older children also consumed more 'Unhealthy' foods. The highest income was associated with the highest consumption of foods of the patterns 'Unhealthy', 'Milk and chocolate' and 'Healthy'.

Conclusions: In view of the results, we emphasize the importance of providing support and encouragement towards EBF in the first months of life, as it can positively influence lifelong eating habits.
\end{abstract}

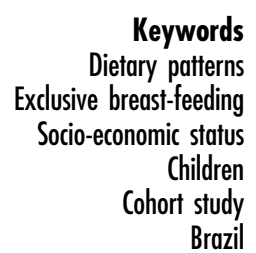

Childhood is the time of life at which there is the greatest tendency to develop inappropriate eating habits. Children are influenced by the family's diet and lifestyle and are subject to changes in environmental and behavioural patterns due to the transition into the school environment ${ }^{(1)}$. There is evidence that dietary habits developed during this stage tend to be maintained ${ }^{(2,3)}$ and influence lifelong health ${ }^{(4,5)}$

Because of changes in population dietary habits, especially since the 1990s, with high consumption of ultraprocessed products, the intake of foods rich in simple carbohydrates, saturated fat and sodium has increased in the daily diet. These types of foods are poor in vitamins, minerals, complex carbohydrates and fibres ${ }^{(6-8)}$ and contribute to the increase in the prevalence of overweight and other cardiometabolic risk factors also among children ${ }^{(8,9)}$.
Thus, it is important to identify inappropriate eating habits in childhood to intervene early and prevent the occurrence of lifelong illness.

Recent studies have evaluated food consumption in the child population using the analysis of dietary patterns ${ }^{(7,10)}$, because individuals do not consume nutrients separately, but rather meals composed of a wide variety of nutrients, which undergo interactions. In this way, some studies have pointed out that socioeconomic characteristics such as income and maternal education are predictors of a child's food consumption, but there is no consensus on this relationship between studies ${ }^{(11-14)}$. In addition, there is evidence that breast-feeding duration may influence the development of eating habits in childhood ${ }^{(15)}$. However, most of these studies evaluated the effect of breast-feeding on the 
consumption of specific food groups rather than on overall food consumption ${ }^{(2,5)}$.

In this context, the present study aimed to identify the dietary patterns of children aged 4-7 years and verify their association with sociodemographic characteristics, lifestyle habits and duration of exclusive breast-feeding (EBF).

\section{Materials and methods}

The present study was retrospective analysis conducted in a cohort of children born in the maternity hospital in Viçosa, Minas Gerais, Brazil. Children were followed up by the Lactation Support Program (PROLAC) during their first year of life. PROLAC is a Program of the Federal University of Viçosa in partnership with the São Sebastião Hospital and the Human Milk Bank of the municipality. The programme's main activities are to provide guidelines for mothers in the postpartum period, aiming to promote breast-feeding and nutritional care to nursing mothers and children in the first year of life.

We selected PROLAC care records for the recruitment of children based on two inclusion criteria: (i) those containing information that allowed location of the child; and (ii) child's date of birth compatible with age between 4 and 7 years at the time of study. Considering these criteria, 669 children were eligible to participate. After at least three attempts to contact children through home visits, 176 were not located (change of address), seventy-five parents did not authorize participation or did not complete all stages of the study, and eight had health problems that prevented them from participating. In addition, seven children were excluded for incomplete food consumption data. Thus, 266 losses were recorded (39.8\%) and the final sample comprised 403 children.

The parent/guardian answered a semi-structured questionnaire to provide sociodemographic information on gender, age, area of residence (urban/rural), maternal education, per capita income, work outside the home (yes/no) and maternal civil status (with/without partner). Maternal education and income were categorized into tertiles for the analysis. Information on EBF ( $\geq 4$ months and $<4$ months) was collected from PROLAC care records.

Information on lifestyle habits was obtained by applying a questionnaire adapted from Andaki ${ }^{(16)}$. The variables evaluated were daily screen time (television, computer, games console) categorized according to the American Academy of Pediatrics' recommendation ${ }^{(17)}(<2 \mathrm{~h}$ and $\geq 2 \mathrm{~h}$ ) and regular physical activity (yes/no).

We obtained information regarding food consumption by evaluating three food records filled out by the parent/ guardian of the child during non-consecutive days, with one day at the weekend. All records were checked and reviewed by the researchers and the parent/guardian to reduce errors when filling out the record form. The data were entered and processed using DietPro ${ }^{\circledR}$ software version $5 \mathrm{i}$.

To assess the dietary patterns, the food items reported in the records were entered with their respective amounts in grams and each child's average consumption of each food item during the three days of investigation was calculated. Afterwards, the foods and preparations were grouped based on their nutritional characteristics or botanical composition $^{(14,18,19)}$, resulting in nineteen food groups (Table 1). Foods or preparations consumed by less than $10 \%$ of the children were redistributed into groups with similar nutritional content.

\section{Data analysis}

The identification of dietary patterns was performed $a$ posteriori by principal component analysis (PCA), which allows food groups to be combined based on the correlations between them. Before proceeding to PCA, we evaluated the adequacy of the sample size, considering that the ratio of cases to food groups should be $\geq 5^{(20)}$. The ratio found in the present study was $21 \cdot 2$ ( 403 children/19 food groups).

To assess the applicability of PCA, the Kaiser-MayerOlkin coefficient was estimated and Bartlett's sphericity test was performed; the Kaiser-Mayer-Olkin coefficient for each variable should be $\geq 0 \cdot 5^{(20)}$ and Bartlett's test of sphericity should be significant. We found a KaiserMayer-Olkin coefficient of 0.561 and $P<0.001$ for Bartlett's test. We also assessed the adequacy of each variable (food group) for PCA, evaluating the anti-image correlation matrix.

To improve interpretation of the factors, we applied orthogonal varimax rotation, which allows the resulting factors not to be correlated ${ }^{(21)}$. The number of factors to be retained was determined based on the Catell (scree plot) chart, where the points of greatest slope indicate the number of factors to be considered in the analysis ${ }^{(21)}$. The interpretability of factor loads was also considered to select the number of components.

Foods or food groups with an absolute factor loading of $\geq 0.25$ were considered to be strongly associated with the component, providing better information for the identification of a dietary pattern. Food groups with a positive factor loading contribute directly to a dietary pattern, while those with a negative factor loading are inversely associated with the pattern ${ }^{(21)}$. When a food was present in more than one pattern, it was maintained in the pattern where it presented the highest factor loading.

A food/food group that presented an absolute factor loading of $\geq 0.25$ in more than one component was standardized to be kept in the group with the highest factor loading. For the designation of dietary patterns, we considered the characteristics of the foods/food groups that contributed the most to each pattern, as well as the nomenclatures used in the literature ${ }^{(14,22,23)}$. 
Table 1 Foods and food groups, categorized according to nutritional characteristics or botanical composition, consumed by children aged 47 years ( $n$ 403), Viçosa, Minas Gerais, Brazil, 2015-2016

\begin{tabular}{|c|c|}
\hline Food/food group & Foods reported in the food records \\
\hline Milk and derivates & Whole milk, cheeses, curd cheese, yoghurt, petit suisse cheese, fermented milk, dairy drinks \\
\hline Chocolate and sugar & Cocoa powder and sugar \\
\hline Coffee and mate tea & Coffee and mate tea \\
\hline Butter and margarine & Butter and margarine \\
\hline Bread, cakes and cookies & $\begin{array}{l}\text { French bread, toast bread, toast, maize biscuit, water and salt biscuit, doughnut, biscuit, potato } \\
\text { biscuit, buttery biscuit, cereal, plain cake, corn cake, chocolate cake }\end{array}$ \\
\hline Filled cookies & Filled cookies \\
\hline Beans & Cooked beans, beans tutu, tropeiro beans, feijoada stew \\
\hline White rice & Cooked white rice \\
\hline Leafy vegetables & $\begin{array}{l}\text { Lettuce, cabbage, mustard, endive, chard, spinach, Barbados gooseberry, broccoli, cauliflower, } \\
\text { parsley, chives, watercress, arugula, corm from elephant-eye plant, cabbage }\end{array}$ \\
\hline Vegetables & $\begin{array}{l}\text { Tomato, onion, cucumber, peppers, zucchini, pumpkin, eggplant, okra, scarlet eggplant, carrot, } \\
\text { beet, pod, chayote, vegetable mayonnaise, vinaigrette }\end{array}$ \\
\hline Tubers, polenta and flours & $\begin{array}{l}\text { Baked potato, mashed potatoes, yams, arracacha, cooked cassava, sweet potatoes, cooked } \\
\text { polenta, polenta, toasted cassava flour (farofa), cassava flour, corn flour }\end{array}$ \\
\hline Fruits & $\begin{array}{l}\text { Banana, apple, orange, clementine, pear, guava, papaya, soursop, avocado, plum, peach, } \\
\text { Barbados cherry, mango, grapefruit, watermelon, melon, strawberry, pineapple, passion fruit, } \\
\text { star fruit, lemon, siriguela, blackberry, jabuticaba, fruit salad }\end{array}$ \\
\hline Natural juice & $\begin{array}{l}\text { Orange, lemon, pineapple, watermelon, acerola, guava, passion fruit, mango, grape, strawberry, } \\
\text { apple, papaya }\end{array}$ \\
\hline Artificial juice and soft drinks & Juice powder, can juice, concentrated juice, soda, cola \\
\hline Meat, fish and eggs & $\begin{array}{l}\text { Cooked beef, fried beef, roasted pork, fried pork, fried fish, cooked fish, cod, sardines, chicken } \\
\text { heart, chicken gizzard, beef liver and chicken liver, boiled egg, fried egg, omelette }\end{array}$ \\
\hline Fried foods, snacks and sausages & $\begin{array}{l}\text { Fried potato, fried cassava, chicken cozinha, kibbeh, hot dog, fried pastel, pot pie, cheese bread, } \\
\text { pasty, chicken pie, leafy pastry, fried nugget, hamburger, pizza, salted popcorn, potato chips, } \\
\text { ham, mortadella, sausage, bacon }\end{array}$ \\
\hline Sweets & $\begin{array}{l}\text { Chocolate, ice cream, popsicle, condensed milk, brigadeiro, party candy, dulce de leche, peanut } \\
\text { candy, cake topped with filling, sweet popcorn, sweet rice, sweet canjica, candies, chewing } \\
\text { gum, gelatine }\end{array}$ \\
\hline Broths and soups & $\begin{array}{l}\text { Vegetable soup, vegetable soup and pasta, canjiquinha, cabbage porridge, chicken soup, green } \\
\text { broth, cassava broth }\end{array}$ \\
\hline Pasta & $\begin{array}{l}\text { Gnocchi, lasagne, meat pancakes, boiled pasta, garlic and oil pasta, pasta noodles, bolognaise } \\
\text { pasta, instant noodles }\end{array}$ \\
\hline
\end{tabular}

After the identification of dietary patterns, we calculated the factor scores for each child in the study. Thus, each child had a factor score in all identified patterns, with a position based on the degree of participation in each pattern $^{(18,22)}$.

Statistical analyses were performed using the statistical software package Stata version 13.0, with normality of the variables evaluated by the Shapiro-Wilk test. The children's consumption scores for each dietary pattern were categorized into tertiles for the association analysis. Simple multinomial logistic regression was applied to evaluate the association between the predictive variables (sociodemographic characteristics, lifestyle habits and $\mathrm{EBF})$ and each dietary pattern (dependent variables). The variables with $P<0.20$ in the bivariate analysis were included in the multivariate logistic regression models to estimate OR and $95 \% \mathrm{CI}$. The final model considered the variables that were associated with the dependent variables at $P<0.05$.

The study was approved by the Ethics Committee for Research with Human Beings of the Federal University of Viçosa (reference number 892476/2014). The children's participation occurred after the parents or guardians signed the Term of Free and Informed Consent.

\section{Results}

The distribution of the sociodemographic, lifestyle and EBF variables in the sample is described in Table 2. More than half of the children evaluated were male (55\%) with age between 6 and 7 years (55\%). We found that the majority of the children $(61 \%)$ received EBF until at least 4 months of life, and most ( $71 \%$ ) children reported screen time of $>2 \mathrm{~h} / \mathrm{d}$. Regarding maternal education, $51 \%$ of mothers reported 8-11 years of schooling.

Table 3 shows the foods/food groups and energy consumed by the studied children. High median values were found for the consumption of milk and milk products $(281 \mathrm{~g} / \mathrm{d})$ and artificial juice and soft drinks $(110 \mathrm{~g} / \mathrm{d})$. However, lower consumption medians were found for leafy vegetables $(7 \mathrm{~g} / \mathrm{d})$, vegetables $(18 \mathrm{~g} / \mathrm{d})$ and natural juices $(28 \mathrm{~g} / \mathrm{d})$.

PCA extracted five dietary patterns, which explained $42 \%$ of the variance in the data (Table 4 ). The first dietary pattern, named 'Traditional', explained $10 \%$ of the variance and consisted of typical foods/food groups present in the Brazilian diet, including: white rice; beans; vegetables; tubers, polenta and flours; and meat, fish and eggs. The 'Unhealthy' pattern was represented mainly by 
Table 2 Distribution of sociodemographic characteristics, lifestyle habits and breast-feeding in the sample of children aged 4-7 years (n 403), Viçosa, Minas Gerais, Brazil, 2015-2016

\begin{tabular}{|c|c|c|}
\hline Variable & $n$ & $\%$ \\
\hline \multicolumn{3}{|l|}{ Gender } \\
\hline Male & 222 & $55 \cdot 1$ \\
\hline Female & 181 & 44.9 \\
\hline \multicolumn{3}{|l|}{ Age } \\
\hline $4-5$ years & 179 & 44.4 \\
\hline $6-7$ years & 224 & $55 \cdot 6$ \\
\hline \multicolumn{3}{|c|}{ Maternal work outside the home* } \\
\hline Yes & 283 & $70 \cdot 6$ \\
\hline No & 118 & $29 \cdot 4$ \\
\hline \multicolumn{3}{|l|}{ Maternal education†,‡ } \\
\hline$<8$ years & 136 & $39 \cdot 1$ \\
\hline $8-11$ years & 202 & $50 \cdot 6$ \\
\hline$>11$ years & 61 & $15 \cdot 3$ \\
\hline \multicolumn{3}{|c|}{ Monthly per capita income†,§ } \\
\hline$R \$ 67.66-224.99$ & 133 & 33.4 \\
\hline$R \$ 225 \cdot 00-340 \cdot 00$ & 154 & $38 \cdot 7$ \\
\hline$R \$ 340 \cdot 01-2500 \cdot 00$ & 111 & $27 \cdot 9$ \\
\hline \multicolumn{3}{|l|}{ Maternal civil status* } \\
\hline With partner & 321 & $80 \cdot 1$ \\
\hline Without partner & 80 & 19.9 \\
\hline \multicolumn{3}{|l|}{ Residential area } \\
\hline Urban & 370 & $91 \cdot 8$ \\
\hline Rural & 33 & $8 \cdot 2$ \\
\hline \multicolumn{3}{|l|}{ EBF until 4 months $\|$} \\
\hline Yes & 241 & $60 \cdot 9$ \\
\hline No & 135 & $39 \cdot 1$ \\
\hline \multicolumn{3}{|l|}{ Screen timeף } \\
\hline$\leq 2 \mathrm{~h} / \mathrm{d}$ & 116 & $29 \cdot 0$ \\
\hline$>2 \mathrm{~h} / \mathrm{d}$ & 284 & $71 \cdot 0$ \\
\hline \multicolumn{3}{|c|}{ Regular practise of physical activity } \\
\hline Yes & 64 & $15 \cdot 9$ \\
\hline No & 339 & $84 \cdot 1$ \\
\hline
\end{tabular}

EBF, exclusive breast-feeding (defined as baby receives only breast milk straight from the mother, or human milk from another source, without any other product or solids).

${ }^{*} n 401$.

†Categorization in tertiles.

$\ddagger n 399$.

§n 398 .

In $n 396$.

II 400.

foods/food groups with high sugar and fat content, such as: artificial juice and soft drinks; fried foods, snacks and sausages; sweets; and stuffed cookies. In addition, the food group broths and soups was negatively (inversely) associated in this pattern.

The 'Milk and chocolate' pattern was so named because it was mainly represented by milk and milk products, and chocolate and sugar, foods that were highly frequently consumed by the children studied. The group coffee and tea was inversely related to this food pattern, indicating that children who consumed milk with chocolate were not in the habit of drinking coffee and tea. The 'Snack' dietary pattern was represented mainly by typical bakery foods, such as: breads, cakes and cookies; butter and margarine; and coffee and tea. The foods/food groups stuffed cookies, fruits and pasta were negatively associated with this pattern. The last pattern, entitled 'Healthy, was represented mainly by natural juice, fruits, vegetables, and broths and soups.

In the bivariate logistic regression analysis (data not shown), children with higher per capita income and
Table 3 Consumption of foods/food groups and energy by children aged 4-7 years ( $n$ 403), Viçosa, Minas Gerais, Brazil, 2015-2016

\begin{tabular}{lcc}
\hline Food/food group (g/d) & Median & Q1-Q3 \\
\hline Milk and derivates & $280 \cdot 8$ & $187 \cdot 5-428 \cdot 3$ \\
Artificial juice and soft drinks & $110 \cdot 0$ & $0-220 \cdot 0$ \\
Beans & $99 \cdot 6$ & $65 \cdot 0-139 \cdot 3$ \\
White rice & $100 \cdot 0$ & $75 \cdot 0-136 \cdot 6$ \\
Meat, fish and eggs & $63 \cdot 3$ & $43 \cdot 3-88 \cdot 6$ \\
Bread, cakes and cookies & $58 \cdot 3$ & $36 \cdot 3-83 \cdot 6$ \\
Fruits & $60 \cdot 0$ & $10 \cdot 0-126 \cdot 7$ \\
Fried foods, snacks and sausages & $40 \cdot 0$ & $18 \cdot 3-75 \cdot 0$ \\
Natural juice & $27 \cdot 5$ & $0-110 \cdot 0$ \\
Coffee and tea & $21 \cdot 6$ & $0-57 \cdot 5$ \\
Vegetables & $17 \cdot 5$ & $5 \cdot 3-35 \cdot 8$ \\
Tubers, polenta and flours & $20 \cdot 0$ & $5 \cdot 0-39 \cdot 1$ \\
Sweets & $13 \cdot 6$ & $0-43 \cdot 3$ \\
Pasta & $13 \cdot 3$ & $0-36 \cdot 6$ \\
Leafy vegetables & $6 \cdot 6$ & $0-14 \cdot 0$ \\
Chocolate and sugar & $10 \cdot 0$ & $0-61 \cdot 3$ \\
Butter and margarine & $1 \cdot 3$ & $0-3 \cdot 3$ \\
Filled cookies & $0 \cdot 0$ & $0-16 \cdot 6$ \\
Broths and soups & $0 \cdot 0$ & $0-30 \cdot 0$ \\
Energy (kJ/d) & 6252.2 & $5382 \cdot 3-7265 \cdot 5$ \\
Energy (kcal) & $1494 \cdot 3$ & $1286 \cdot 2-1738 \cdot 5$ \\
\hline
\end{tabular}

Q1, quartile 1 (25th percentile); Q3, quartile 3 (75th percentile).

mothers with higher education showed greater adherence to the 'Unhealthy', 'Milk and chocolate' and 'Healthy' patterns $(P<0.005)$. Children with screen time of $>2 \mathrm{~h} / \mathrm{d}$ $(P=0.003)$ and those aged 6 and 7 years $(P=0.001)$ were more likely to consume more 'Unhealthy' foods. The older children (aged 6 and 7 years) showed lower adherence to the 'Milk and chocolate' pattern, compared with children aged 4 and 5 years $(P=0 \cdot 024)$. Children who received EBF until at least 4 months of life had moderate adherence (second tertile) to the 'Snack' pattern $(P=0 \cdot 026)$.

Table 5 shows the final models of the multivariate logistic regression analysis for each dietary pattern (dependent variables) and sociodemographic characteristics, lifestyle habits and $\mathrm{EBF}$ (independent variables). As in the simple model, no variable was associated with the 'Traditional' pattern. Even after adjustment, children with higher per capita income showed higher adherence to the 'Unhealthy', 'Milk and chocolate' and 'Healthy' patterns $(P<0.05)$.

Older children (aged 6 and 7 years) had a 2.25 times greater chance of consuming 'Unhealthy' foods than children aged 4 and 5 years. In addition, children who did not receive $\mathrm{EBF}$ until at least 4 months of life also had higher adherence to this pattern ( $\mathrm{OR}=1 \cdot 71 ; 95 \%$ CI $1 \cdot 02,2 \cdot 86)$. After adjustment in the multivariate model, the association between lower EBF duration and moderate food consumption of the 'Snack' pattern was maintained ( $\mathrm{OR}=$ $1 \cdot 76 ; 95 \%$ CI $1 \cdot 06,2 \cdot 90$ ).

\section{Discussion}

The present study identified five dietary patterns ('Traditional,' 'Unhealthy', 'Milk and chocolate', 'Snack' and 
Table 4 Dietary patterns and factor loadings of foods/food groups consumed by children aged 4-7 years (n 403), Viçosa, Minas Gerais, Brazil, 2015-2016

\begin{tabular}{|c|c|c|c|c|c|}
\hline \multirow[b]{2}{*}{ Food/food group } & \multicolumn{5}{|c|}{ Dietary pattern* } \\
\hline & Traditional & Unhealthy & Milk and chocolate & Snack & Healthy \\
\hline Milk and derivates & -0.038 & -0.234 & 0.738 & $0 \cdot 164$ & -0.018 \\
\hline Chocolate and sugar & -0.026 & 0.028 & 0.856 & 0.028 & -0.050 \\
\hline Coffee and tea & 0.036 & -0.234 & -0.502 & 0.252 & $-0 \cdot 181$ \\
\hline Butter and margarine & 0.194 & 0.182 & 0.034 & 0.573 & -0.027 \\
\hline Bread, cakes and cookies & 0.044 & 0.032 & -0.012 & 0.703 & 0.091 \\
\hline Stuffed cookies & -0.111 & 0.273 & 0.105 & -0.381 & -0.026 \\
\hline Beans & 0.684 & -0.159 & -0.102 & -0.139 & 0.110 \\
\hline White rice & 0.749 & 0.004 & -0.144 & -0.043 & $-0 \cdot 161$ \\
\hline Leafy vegetables & 0.499 & -0.051 & 0.073 & 0.178 & 0.256 \\
\hline Vegetables & 0.371 & 0.031 & 0.002 & 0.055 & 0.433 \\
\hline Tubers, polenta and flours & 0.381 & -0.080 & 0.017 & 0.204 & -0.019 \\
\hline Fruits & 0.125 & -0.114 & 0.115 & -0.273 & 0.532 \\
\hline Natural juice & -0.132 & 0.034 & -0.051 & 0.231 & 0.620 \\
\hline Artificial juice and soft drinks & -0.127 & 0.755 & 0.020 & 0.001 & -0.083 \\
\hline Meat. fish and eggs & 0.408 & 0.329 & 0.093 & $0 \cdot 122$ & $-0 \cdot 142$ \\
\hline Fried foods, snacks and sausages & -0.088 & 0.631 & -0.106 & -0.028 & 0.067 \\
\hline Sweet & 0.010 & 0.477 & 0.031 & -0.144 & 0.443 \\
\hline Broth and soups & -0.090 & -0.334 & -0.021 & 0.049 & 0.306 \\
\hline Pasta & 0.052 & 0.151 & -0.072 & -0.458 & 0.027 \\
\hline$\%$ of variance explained & $9 \cdot 8$ & $9 \cdot 0$ & 8.5 & 8.0 & $7 \cdot 0$ \\
\hline Total variance explained (\%) & & & $42 \cdot 3$ & & \\
\hline
\end{tabular}

*Dietary patterns were extracted by principal component analysis with varimax rotation and Kaiser normalization, and named through main components. Bold values indicate absolute factor loadings $\geq 0 \cdot 25$.

Table 5 Final models of the multinomial logistic regression analysis for the association of sociodemographic characteristics, lifestyle habits and breast-feeding with tertiles of consumption of dietary patterns (outcomes) among children aged 4-7 years ( $n$ 403), Viçosa, Minas Gerais, Brazil, 2015-2016

\begin{tabular}{|c|c|c|c|}
\hline & OR & $95 \% \mathrm{Cl}$ & $P$ value \\
\hline \multicolumn{4}{|l|}{ Unhealthy pattern* } \\
\hline Children aged 6 and 7 years & $2 \cdot 25$ & $1.34,3.77$ & 0.002 \\
\hline Third tertile of per capita income & $2 \cdot 47$ & $1.35,4.54$ & 0.003 \\
\hline EBF for $<4$ months & 1.71 & $1.02,2 \cdot 86$ & 0.040 \\
\hline \multicolumn{4}{|l|}{ Milk and chocolate pattern $†$} \\
\hline Third tertile of per capita income & $2 \cdot 84$ & $1.48,5.45$ & 0.002 \\
\hline \multicolumn{4}{|c|}{ Snack pattern $\ddagger$ (second tertile of consumption scores) } \\
\hline EBF for $<4$ months & $1 \cdot 76$ & $1.06,2.90$ & 0.027 \\
\hline \multicolumn{4}{|l|}{ Healthy pattern§ } \\
\hline Third tertile of per capita income & 2.94 & $1.43,6.05$ & 0.003 \\
\hline
\end{tabular}

EBF, exclusive breast-feeding.

${ }^{*}$ Adjusted for gender, age, per capita income, maternal work, screen time and EBF duration.

†Adjusted for age, per capita income, maternal work, civil status and physical activity practise.

$\ddagger$ Adjusted by for age, maternal education, civil status, physical activity practise and EBF duration.

$\S A d j u s t e d$ for gender, age, per capita income and physical activity practise.

'Healthy') that represented the overall dietary habits of the children evaluated and explained $42 \%$ of the original data variance. Other studies carried out to determine the dietary patterns in Brazilian children showed similarities with our study. Most of them identified a dietary pattern composed mainly of foods that are part of the population's eating habits such as rice, beans, tubers and meat, commonly called 'Traditional'. The other characteristic patterns found in the studies showed the consumption of foods rich in refined sugars, fats and sodium, named the 'Unhealthy' pattern in our study, and a 'Healthy' pattern which is based on foods such as fruits, vegetables and natural juices ${ }^{(14,23,24)}$.
In another study carried out in Viçosa, Minas Gerais, Brazil, Villa et $a l .{ }^{(14)}$ identified among children aged 8 and 9 years a dietary pattern composed of milk and chocolate, which they named as 'Monotone', confirming that the consumption of milk added by chocolate is part of the eating habits of the children in the municipality. These authors found that the mean consumption of chocolate was $18.7 \mathrm{~g} / \mathrm{d}$, above the mean found in our study ( $14 \mathrm{~g} / \mathrm{d}$ ). Another study carried out in southern Brazil with children aged 1-6 years also identified a pattern containing milk and chocolate. The authors suggested that children who adhere to this pattern probably do not consume main meals properly, replacing them with quick snacks, such as chocolate milk ${ }^{(24)}$. 
The 'Snack' pattern identified in the present study was also observed in pre-school children from Diamantina, Minas Gerais, Brazil, based mainly on bakery products and butter/margarine ${ }^{(23)}$. A cohort study of Chinese children aged 13 months and 6 years identified a food pattern composed mainly of refined carbohydrates and confectionery products ${ }^{(25)}$.

In fact, the food patterns identified in the present study, except the 'Healthy' one, were in line with the worldwide trend of frequent consumption of ultra-processed foods by children that are high in fat and refined carbohydrates, such as baked goods, sausages, sweetened beverages and sweets $^{(14,23,26)}$. The excessive consumption of these foods in association with a sedentary lifestyle is related to risk of developing overweight and cardiometabolic diseases in the child population ${ }^{(5,25,27,28)}$.

An interesting result of our study was the association of income with the dietary patterns 'Unhealthy' and 'Milk and chocolate', composed mainly of foods high in fat and refined sugars. A similar result was observed in Nobre et al.'s study ${ }^{(23)}$ in Brazil, in which children belonging to higher-income families had higher participation in the pattern based on unhealthy foods, such as sweets, sodas and stuffed cookies. However, in a study carried out in Spain, low-income children and adolescents were more likely to consume unhealthy foods ${ }^{(29)}$.

Higher consumption of the 'Healthy' pattern was also associated with higher per capita income. This result corroborates the results of a multicentre study with children aged 2-9 years in Europe, where children whose parents had higher income and schooling consumed more healthy foods ${ }^{(12)}$. However, the authors emphasize that the average consumption of foods belonging to this pattern, such as fruits and vegetables, was low. We also observed low average consumption of these foods among the children assessed, mainly leafy vegetables and natural juices. While the mean consumption of artificial juices and soft drinks was $148 \mathrm{ml} / \mathrm{d}$, the consumption of natural juices was $71 \mathrm{ml} / \mathrm{d}$, evidencing the trend of consumption of industrialized sweetened drinks by children which has been associated with unfavourable health outcomes ${ }^{(4,8)}$.

No sociodemographic, lifestyle or breast-feeding variables were related to the 'Traditional' dietary pattern after adjustment of the multivariate model. Thus, it is suggested that regardless of income, EBF duration and lifestyle, most of the children frequently consumed the 'Traditional' dietary pattern, which is composed of the typical Brazilian foods such as rice and beans. However, other studies have found an association between food consumption of the 'Traditional' dietary pattern and household income. Villa et al. ${ }^{(14)}$ observed that children of lower socio-economic level showed greater adherence to this pattern. However, other works identified an inverse association of the 'Traditional' pattern with lower socio-economic level ${ }^{(12,24)}$.

Although maternal work outside the home was not associated with any of the dietary patterns in our study, most children with the highest per capita income were those whose mothers worked. Thus, it is believed that the inclusion of women in the labour market makes it difficult to prepare meals, which leads to greater consumption of foods outside the home, especially industrialized foods ${ }^{(27)}$.

The bivariate analysis showed that children with screen time of more than $2 \mathrm{~h} / \mathrm{d}$ presented higher intake of foods from the 'Unhealthy' pattern, but after adjusting for other variables in the multivariate model, the association was not maintained. In a study conducted with American schoolchildren, it was found that those with greater daily time in front of a television and games console were more likely to consume fast foods and sugary drinks ${ }^{(13)}$. The broadcasting and encouragement of television advertising for processed food products, especially ultra-processed products, is a factor that influences the high consumption of these foods by children, especially those who spend most of their free time in sedentary activities ${ }^{(30)}$.

The current study presents novel results on the relationship of EBF for less than 4 months with the consumption of foods of the 'Unhealthy' and 'Snack' patterns, after adjustment, in the multivariate models. Apparently, only one study has previously used PCA to investigate the influence of EBF during the early months of life on childhood food patterns ${ }^{(31)}$, showing that EBF duration was positively associated with the 'Healthy' pattern. These authors found associations between breast-feeding only and the 'Healthy' pattern, to which breast-fed children showed greater adherence. Perrine et $_{\text {al }}{ }^{(2)}$, who evaluated the association of EBF with the consumption of certain food groups by 6-year-olds, identified that breast-feeding duration was inversely associated with consumption of sugary drinks. Soldateli et ll $^{(3)}$ found no association between lactation time and consumption of fruits and vegetables by children at 4-7 years of age.

Infant dietary behaviour develops early and is influenced by different factors, including maternal diet during the intra-uterine phase ${ }^{(32)}$. Breast-fed children can taste different flavours of the foods consumed by the mother. This provides greater variation of the palate, when compared with children fed formula. Thus, studies have shown that children who receive breast milk have better acceptance of new foods, especially fruits and vegetables, and dietary habits tend to remain in later stages of life ${ }^{(1,32)}$.

As a possible limitation in the present study, we emphasize the subjectivity during the identification of food patterns in several stages of the analysis, such as the criteria used to group foods, the number of factors to be retained and in the way the identified patterns are named. However, to minimize the effects of this limitation, the criteria adopted during all stages of the analysis were described in detail. As a positive point, we highlight the use of three food records for evaluation of consumption, which reduces the intra-individual variability of intake and allows us to investigate the habitual food consumption of the children. In addition, the use of recorded data 
on breast-feeding duration is emphasized, avoiding memory bias.

\section{Conclusion}

In conclusion, we identified five dietary patterns in children aged 4-7 years. The highest per capita income was associated with high consumption of foods from the 'Unhealthy', 'Milk and chocolate' and 'Healthy' patterns. Children who were not exclusively breast-fed until 4 months of life showed more adherence to the 'Unhealthy' and 'Snack' patterns, and older children aged 6 and 7 years also consumed more foods of the 'Unhealthy' pattern.

In view of the identified food patterns, most of them based mainly on foods high in sugars, fats and sodium, it is necessary to implement public food and nutrition policies directed to children, since eating habits are established during childhood and when inadequate and maintained throughout life, they can lead to the development of diseases. In addition, the importance of support and encouragement of EBF during the first months of life is emphasized, which, in addition to the many benefits already confirmed, can positively influence lifelong eating habits.

\section{Acknowledgements}

Acknowledgements: The authors thank the National Council for Scientific and Technological Development (CNPq) and the Foundation for Research Support of the State of Minas Gerais (FAPEMIG) for the financial support; the Coordination for the Improvement of Higher Education Personnel (CAPES) for granting a scholarship; and the children, parents and guardians for participating in the study. Financial support: This work was supported by CNPq (grant number 485124/2011-4) and FAPEMIG (grant number 02055-13). CNPq, FAPEMIG and CAPES had no role in the design, analysis or writing of this article. Conflict of interest: The authors declare that they have no conflicts of interest. Authorship: S.A.V. assisted the conception and design of this work, assisted the data collection, analysis and interpretation of the data, conducted the literature search, as well as wrote the manuscript. P.C.A.F. and C.S.A. assisted the conception and design of this work, assisted the data collection, analysis and interpretation, as well as revised and approved the final version to be published. H.H.M.H., A.Q.R., P.F.P. and S.E.P. revised and approved the final version to be published. S.C.C.F. designed the study including the data collection, coordinated and supervised and approved the final version to be published. Ethics of buman subject participation: This study was conducted according to the guidelines laid down in the Declaration of Helsinki and all procedures involving human subjects were approved by the Ethics Committee on Human Research of the Federal University of Viçosa (case number 892476/2014). All participants, as well as their responsible adults, were informed about the objectives of the research and informed consent was obtained from all children's parents/guardians.

\section{References}

1. Vitolo MR, Rauber F, Campagnolo PD et al. (2010) Maternal dietary counseling in the first year of life is associated with a higher healthy eating index in childhood. J Nutr 140, 2002-2007.

2. Perrine CG, Galuska DA, Thompson MPH et al. (2014) Breastfeeding duration is associated with child diet at 6 years. Pediatrics 134, 50-55.

3. Soldateli B, Vigo A \& Giugliane ERJ (2016) Effect of pattern and duration of breastfeeding on the consumption of fruits and vegetables among preschool children. PLos One 11, e0148357.

4. Dishchekenian VRM, Escrivão MAMS, Palma D et al. (2011). Dietary patterns of obese adolescents and different metabolic effects. Rev Nutr 24, 17-29.

5. Zarrinpar A, Chaix A \& Panda S (2016) Daily eating patterns and their impact on health and disease. Trends Endocrinol Metab 27, 69-83.

6. Brazilian Institute of Geography and Statistics (2010) Survey of Family Budgets 2008-2009. Anthropometry and Nutritional Status of Children, Adolescents and Adults in Brazil. Rio de Janeiro, RJ: IGBE.

7. Kiefte de Jong JC, Vries JH et al. (2013) Socio-demographic and lifestyle determinants of 'Western-like' and 'Health conscious' dietary patterns in toddlers. Br J Nutr $\mathbf{1 0 9}$, $137-147$.

8. Rinaldi AEM, Gabriel GFCP, Moreto F et al. (2016) Dietary factors associated with metabolic syndrome and its components in overweight and obese Brazilian schoolchildren: a cross-sectional study. Diabetol Metab Syndr 8, 58.

9. Sparrenberger K, Friedrich RR, Schiffner MD et al. (2015) Ultra-processed food consumption in children from a Basic Health Unit. J Pediatr (Rio J) 91, 535-542.

10. Voortman T, Leermakers ETM, Franco OH et al. (2016) $A$ priori and a posteriori dietary patterns at the age of 1 year and body composition at the age of 6 years: the Generation R Study. Eur J Epidemiol 31, 775-783.

11. Silva RC, Assis A.M, Szarfarc SC et al. (2012) Socioeconomic inequality shaping the dietary patterns of children and teens. Rev Nutr 25, 451-461.

12. Fernandez-Alvira JM, Rnhorst CB, Bammann K et al. (2015) Prospective associations between socio-economic status and dietary patterns in European children: the Identification and Prevention of Dietary- and Lifestyle-induced Health Effects in Children and Infants (IDEFICS) Study. Br J Nutr $\mathbf{1 1 3}, 517-525$.

13. Lowry R, Michael S, Demissie Z et al. (2015) Associations of physical activity and sedentary behaviors with dietary behaviors among US high school students. J Obes 2015, 876524.

14. Villa JKD, Silva AR, Santos TSS et al. (2015) Dietary patterns of children and socioeconomical, behavioral and maternal determinants. Rev Paul Pediatr 33, 302-309.

15. Maier AS, Chabanet C, Schaal B et al. (2008) Breastfeeding and experience with variety early in weaning increase infants' acceptance of new foods for up to two months. Clin Nutr 27, 849-857. 
16. Andaki ACR (2010) Anthropometry and level of physical activity in predicting metabolic changes in 10-year-old children. Master's Thesis, Federal University of Viçosa.

17. American Academy Pediatrics, Committee on Public Education (2001) Children, adolescents, and television. Pediatrics 107, 423-426.

18. Hu FB (2002) Dietary pattern analysis: a new direction in nutritional epidemiology. Curr Opin Lipidol 13, 3-9.

19. Matos SMA, Barreto ML, Rodrigues LC et al. (2014) Dietary patterns of children under five years of age living in the State capital and other counties of Bahia State, Brazil, 1996 and 1999-2000. Cad Saude Publica 30, 44-54.

20. Hair JF, Anderson RE, Tatham RL et al. (2005) Análise Multivariada de Dados, 9th ed. Porto Alegre, RS: Bookman5.

21. Olinto MT (2007) Dietary patterns: principal components analysis. In Epidemiologia Nutricional, pp. 213-226 [G Kag, $\mathrm{R}$ Sichieri and DP Gigante, organizadores]. Rio de Janeiro, RJ: Fiocruz/Atheneu.

22. Salvatti AG, Escrivão MAMS, Taddei JAAC et al. (2011) Eating patterns of eutrophic and overweight adolescents in the city of São Paulo, Brazil. Rev Nutr 24, 703-713.

23. Nobre L, Lamounier JA \& Franceschini SCC (2012) Preschool children dietary patterns and associated factors. $J$ Pediatr (Rio J) 88, 129-136.

24. Souza RLV, Madruga SW, Gigante DP et al. (2013) Dietary patterns and associated factors among children one to six years of age in a city in southern Brazil. Cad Saude Publica 29, 2416-2426.
25. Hooven EHV, Heppe DHM, Kiefte de Jong JC et al. (2015) Infant dietary patterns and bone mass in childhood: the Generation R Study. Osteoporos Int 26, 1595-1604.

26. World Health Organization (2003) Diet, Nutrition and the Prevention of Chronic Diseases. Joint WHO/FAO Expert Consultation. WHO Technical Report Series no. 916. Geneva: WHO.

27. Rinaldi AE, Pereira AF, Macedo CS et al. (2008) Feeding practices and physical inactivity contributions to childhood overweight. Rev Paul Pediatr 26, 271-277.

28. Santos NHA, Fiaccone R, Barreto M.L et al. (2014) Association between eating patterns and body mass index in a sample of children and adolescents in Northeastern Brazil. Cad. Saude Publica 30, 2235-2245.

29. Aranceta J, Perez-Rodrigo C, Ribas L et al. (2003) Sociodemographic and lifestyle determinants of food patterns in Spanish children and adolescents: the enKid study. Eur J Clin Nutr 57, Suppl. 1, 40-44.

30. Story M \& Faulkner P (1990) The prime time diet: a content analysis of eating behavior and food messages in television program content and commercials. Am J Public Health 80, $738-740$.

31. Grieger JA, Scott J \& Cobiac L (2011) Dietary patterns and breast-feeding in Australian children. Public Health Nutr 14 1939-1947.

32. Beauchamp GK \& Mennella JA (2009) Early flavor learning and its impact on later feeding behavior. J Pediatr Gastroenterol Nutr 48, Suppl. 1, 25-30. 